\title{
EVOLUÇÃO DO CONTROLE BIOLÓGICO DE INSETOS E PRAGAS NO SETOR CANAVIEIRO: UMA ANÁLISE NA PERSPECTIVA ECO- NÔMICA
}

\author{
Adriano Renzi* \\ Aline Patrícia Henz** \\ César Benites Mário Zidora*** \\ Pery Francisco Assis Shikida****
}

RESUMO: O artigo objetiva apresentar, na perspectiva econômica, as contribuições acadêmicas relacionadas à utilização do controle biológico na cultura canavieira. Metodologicamente a pesquisa é qualitativa e foi realizada uma revisão de literatura e análise documental e bibliográfica usando os termos controle biológico, produtividade e custos de produção. Conclui-se que o controle biológico nessa cultura desempenha um papel importante na expansão da produção agrícola e dos produtos derivados da cana. Os resultados destacaram a relevância das análises de custo-benefício para sustentabilidade, aperfeiçoando as técnicas de controle biológico no setor canavieiro, porém foi visto que o tema não é tratado com frequência pelos acadêmicos da economia rural e agronegócio.

PALAVRAS-CHAVE: Cana-de-açúcar; Controle biológico; Custos de produção; Produtividade.

\section{EVOLUTION OF BIOLOGICAL CONTROL OF INSECTS AND PESTS IN SUGAR CANE CROPS: AN ANALYSIS FROM THE ECONOMIC PERSPECTIVE}

ABSTRACT: Academic contributions related to the use of biological control in sugar cane crops are provided from the economic perspective. Current qualitative re-

Docente da Universidade Federal da Grande Dourados (UFGD), Dourados (MS), Brasil. Doutorando do Programa de Pós-Graduação em Desenvolvimento Regional e Agronegócios, Universidade Estadual do Oeste do Paraná, Toledo (PR), Brasil. E-mail: adrianorenzi@ufgd.edu.br

** Docente da Universidade Estadual do Oeste do Paraná (UNIOESTE), Foz do Iguaçu (PR), Brasil. Doutoranda do Programa de Pós-Graduação em Desenvolvimento Regional e Agronegócios, Universidade Estadual do Oeste do Paraná, Toledo (PR), Brasil.

*** Doutorando do Programa de Pós-Graduação em Desenvolvimento Regional e Agronegócios, Universidade Estadual do Oeste do Paraná, Toledo (PR), Brasil.

***** Docente do Programa de Pós-Graduação em Desenvolvimento Regional e Agronegócios, Universidade Estadual do Oeste do Paraná, Toledo (PR), Brasil. 
search comprises a review of the literature, documental and bibliographical analysis with the terms biological control, productivity, production costs. Results show that biological control of sugar cane crops has an important role in the expansion of agricultural production and of cane-derived products. They also underscored the relevance of costs-benefits analyses for sustainability with the improvement of biological control techniques in the sugar cane sector. The theme has not been studied often by undergraduates in rural economy and agribusiness.

KEY WORDS: Sugar cane; Biologic control; Production costs; Productivity.

\section{INTRODUÇÃO}

A história da cultura da cana-de-açúcar nos últimos cinco séculos se entrelaça com a história do Brasil e do mundo. A longa convivência relativa ao sistema produtivo com esse produto agrícola tornou o Brasil o líder mundial em qualidade e quantidade na produção canavieira, assim como de seus principais derivados, o açúcar e o etanol (SHIKIDA, 2015). O açúcar é um dos produtos fundamentais para a questão da segurança alimentar, enquanto a produção do biocombustível etanol volta-se para fins energéticos, sendo o Brasil, atualmente, o maior produtor de açúcar e o segundo maior produtor de etanol no mundo (RFA, 2016) 5 . Tal produto é uma fonte de combustível renovável, em substituição aos combustíveis fósseis, acompanhado pelo baixo custo de produção, se comparado a outras fontes alternativas e às condições de produção observadas em outros países.

Afora o destaque da agroindústria canavieira na história, saúde e na questão dos biocombustíveis, vale ressaltar a importância dessa atividade principalmente no Nordeste brasileiro. Com efeito, entre 1530 a 1650, o ciclo do açúcar marcou a economia brasileira, sendo esta baseada nas exportações açucareiras. Nessa fase, o cultivo da cana expandiu-se em faixas litorâneas, ocupando terras das capitanias de Pernambuco, Bahia, São Tomé (hoje Rio de Janeiro) e São Vicente (hoje São Paulo), sendo Pernambuco a que mais prosperou durante o período colonial. Os elementos caracterizadores dessa exploração agrícola foram: o latifúndio (grande propriedade

\footnotetext{
5 Em 2015 o Brasil produziu 26,85 milhões de litros de etanol, enquanto os EUA lideram com 56,05 milhões
} de litros (RFA, 2016). 
rural onde era cultivada a cana-de-açúcar e onde estava instalado o Engenho - unidade responsável pela fabricação do açúcar); o trabalho escravo; e a monocultura (FURTADO, 1974). Esta sociedade estava estruturada em classes rígidas, assim descritas: os donos de engenho, grandes comerciantes e os altos funcionários reais que detinham o poder econômico/político; a classe média formada por prestadores de serviços; a classe baixa, constituída por pessoas pobres e que também prestavam serviços; e os escravos (ANDRADE, 2001). Esta caracterização polarizada em termos de classes marcou a história cultural do Brasil, sendo ainda hoje uma marca entre aqueles que detêm o poder econômico/político dos que não o detêm.

A agroindústria canavieira no Brasil representa uma riqueza em torno de $2 \%$ do Produto Interno Bruto (PIB) e é responsável por aproximadamente um milhão de postos de trabalho formais. Isto representa a geração de US\$ 738 milhões em termos de massa salarial. Além do açúcar e do etanol, esta agroindústria produz vários derivados com usos alternativos (melaço, aguardente, torta de filtro, bagaço de cana, etc.), dos quais se destaca a cogeração de energia oriunda da utilização do bagaço da cana, que representa 15,7\% da energia do país (NEVES; CONEJERO, 2010).

O Brasil é o maior produtor mundial de cana-de-açúcar, sendo que entre 2005 e 2015 a área colhida aumentou em 67,01\%, o que representa um incremento na área de produção a uma taxa de crescimento média geométrica de 5,76\% no período. São Paulo destacou-se como maior produtor brasileiro, com 59,75\% da cana-de-açúcar brasileira e um aumento de 59,56\% em termos de área colhida. Em 2015 esta cultura ocupava cerca de 10,9 milhões de hectares de área plantada, sendo sua produção realizada majoritariamente nas regiões Centro-Sul $(85,10 \%)$ e Norte-Nordeste $(14,90 \%)$, com dois períodos diferentes de colheita: de abril a dezembro na região Centro-Sul, e de setembro a março na região Norte-Nordeste (UNICA, 2015).

Em 2015, o setor do agronegócio representou 21,35\% do PIB brasileiro. Contudo, os dados do relatório do PIB das cadeias, elaborado pelo Centro de Estudos Avançados em Economia Aplicada - CEPEA (2015), indicam que a cadeia da cana-de-açúcar cresceu, no primeiro semestre de 2015 , a taxa de $1,71 \%$ e a renda originária dessa atividade registrou crescimento de 1,2\%. De acordo com esse relatório, isso foi decorrente da perspectiva de maior produtividade dos canaviais que, por sua vez, elevou as estimativas de produção. 
A atividade agropecuária, a exemplo da agricultura canavieira, envolve dois tipos de riscos. O primeiro está relacionado com a produção, no caso da dependência de fatores climáticos e controle de pragas e doenças, já o segundo risco advém do preço das commodities no mercado. Os riscos relacionados com a produção (objeto deste estudo), podem ser resolvidos com o uso de tecnologias específicas, como o caso de lavouras adequadas e método apropriado de controle de pragas e doenças. Os prejuízos causados pelas pragas e doenças têm impactos significativos no rendimento vegetal da cultura, o que resulta em perdas econômicas, na maior parte dos casos, dependendo do grau de severidade do ataque, até $50 \%$ da produção pode ser perdida. Alguns métodos de controle têm sido utilizados no intuito de combater as pragas e doenças para evitar o desperdício em termos econômicos, a exemplo do método químico (agrotóxicos), todavia, não é sustentável e coloca em risco o equilíbrio ecológico, incorrendo em altos custos sociais em geral. Uma das premissas básicas de boas práticas agrícolas no cenário econômico internacional é a opção pela agricultura sustentável, devido às externalidades negativas que os defensivos agrícolas provocam no meio ambiente e na saúde dos seres humanos.

Sendo assim, devido à contribuição que o setor canavieiro representa na economia brasileira, o controle biológico de pragas e doenças surge como uma alternativa para viabilizar a produção canavieira em termos ambientais, sociais e econômicos ou ainda o controle biológico aparece como o mais adequado por ser ambientalmente amigável em não danificar e nem modificar o estado natural do meio ambiente, isto é, desenvolve-se sistemas de cultivo sustentáveis que sejam menos dependentes de agrotóxicos (BETTIOL; MORANDI, 2009).

A partir dessa constatação e com a perspectiva de contribuir para ampliação da produtividade da cana-de-açúcar, este artigo tem como objetivo apresentar, na perspectiva econômica, as contribuições acadêmicas relacionadas à relevância da utilização do controle biológico na expansão e no aumento da produtividade nessa cultura e, em decorrência, preencher essa lacuna pouco explorada academicamente a partir de uma revisão de literatura.

A revisão de literatura foi utilizada na última etapa deste estudo, na apresentação de um quadro com as publicações de artigos em periódicos, referentes ao controle biológico da cana-de-açúcar e sua relação com a produtividade e custos 
econômicos nacionais e internacionais. Para tanto, foi realizada uma consulta nas bases de dados do Portal Capes; Web of Science; Science Direct; e Scopus entre 1990 e 2016. O intuito da utilização desta modalidade de pesquisa foi demonstrar que os estudos nesta temática são restritos, o que caracteriza a necessidade de exploração do tema para fins de futuras pesquisas aplicadas.

O artigo está organizado em quatro seções. Além desta introdução, a segunda seção aborda a importância do controle biológico na cultura canavieira no Brasil. Na sequência apresenta-se a revisão de literatura, e por fim as considerações finais.

\section{A IMPORTÂNCIA DO CONTROLE BIOLÓGICO NA CULTURA CANAVIEIRA}

Ainda que considerado atualmente um dos maiores produtores mundiais de alimentos, o Brasil foi um grande importador até a década de 1960, com menor efeito até 1980, período marcado pela industrialização. A partir de 1990, diante da estabilidade macroeconômica, melhores preços das commodities no mercado agrícola mundial e inserção de novas tecnologias, o agronegócio nacional experimentou um novo período, marcado, a partir de então, por investimentos em pesquisas e tecnologias (PEREIRA et al., 2012).

O setor agrícola brasileiro exerce um papel importante ao garantir valores recordes nas exportações, contribuindo para a geração de divisas ${ }^{6}$. Apesar do destaque internacional, o desempenho agrícola brasileiro depende de poucos produtos na pauta de exportações, sendo assim, além do estímulo à produção, percebe-se ainda o encaminhamento à diversificação de produtos, que induz ainda mais o desenvolvimento de tecnologias para o setor (SANTOS et al., 2016).

Com a expansão das fronteiras agrícolas no Brasil, as pesquisas, principalmente de interesse empresarial, têm sido direcionadas para a adaptação de sementes em diferentes ambientes climáticos, por meio de melhoramento genético e uso de novos fertilizantes e agroquímicos para a transformação do espaço agrícola. Um exemplo é o desenvolvimento do cerrado, onde houve melhoria do solo para pro-

$\overline{6}$ Dessa forma, percebe-se que duas funções básicas do agronegócio têm sido efetivas: (1) proporcionar alimentos para população total; e (2) fornecer divisas para a compra de insumos e bens de capital necessários ao desenvolvimento de atividades econômicas. Sobre as outras três funções, ver Bacha (2012). 
dução agropecuária, que transformou a região em uma grande produtora de grãos e carne bovina (PEREIRA et al., 2012).

No entanto, a preocupação mundial com a produção agrícola não se refere apenas ao aspecto econômico, mas também a uma questão social de demanda cada vez maior de alimentos, decorrente do crescimento populacional. Além disso, a tecnologia é utilizada não apenas para atingir melhores índices de produtividade e variação regional, mas também como estratégia para controle de pragas e doenças mediante uso de agrotóxicos. Atualmente, os investimentos em pesquisa e desenvolvimento caminham para práticas de melhoramento biológico com impacto também na qualidade dos alimentos e garantias à saúde da população (BUAINAIN et al., 2013).

Intensificando a produção e apoiando-a no uso de sementes melhoradas, insumos industriais, máquinas, água e gestão produtiva, submetidos à racionalidade econômica, não houve neutralidade do ponto de vista social, e nem inócua, do ponto de vista ambiental. As críticas à agricultura moderna, uma justa reação aos abusos no uso de produtos químicos na agricultura, são feitas em diversos níveis sociais e não se limitam a um país ou região, e ganharam mais força com a emergência dos temas ambientais e o fenômeno global das mudanças climáticas (BUAINAIN et al., 2013).

O modelo de produção agrícola tradicional, além de acarretar problemas ambientais como erosões e contaminação dos solos e mananciais, apresentou ainda a resistência de pragas e fitopatógenos ao uso massivo de agrotóxicos. Adicionalmente, emergiu o debate acerca de práticas com menor impacto ambiental na agricultura, com necessidade de estratégias de desenvolvimento baseadas em princípios sustentáveis, enfatizando as características e desdobramentos sobre as dimensões sociais, econômicas e ecológicas (BETTIOL; MORANDI, 2009; PAULA JÚNIOR et al., 2016).

As tecnologias agrícolas alicerçadas em uma estratégia de crescimento verde, realizadas por meio da proteção do meio ambiente a longo prazo, com a utilização dos recursos naturais a partir dos princípios de capacidade de carga, podem, simultaneamente, oferecer um padrão de vida aceitável e reduzir os índices de pobreza. Esse modelo de produção está em prática e tem sido cada vez mais utilizado 
pelos produtores rurais brasileiros. Entretanto, a forma como os mecanismos de financiamento das inovações brasileiras é construída, torna-se crucial intensificar a aceitação da tecnologia em larga escala (MARTHA-JÚNIOR; ALVES; CONTINI, 2012).

Entre 1975 e 2012, Gasques et al. (2014) enfatizam que o Brasil obteve as melhores taxas de crescimento da produtividade da agricultura, sendo que a produtividade total dos fatores (PTF) correspondeu a 3,52\% ao ano. Nessa perspectiva, para Aguiar Menezes (2003), o desafio da agricultura é continuar mantendo o nível de produtividade da produção agrícola e, simultaneamente, aperfeiçoar a qualidade biológica (valor nutritivo) e reduzir a quantidade de resíduos tóxicos nos alimentos, além de realizar esses processos a partir da preservação dos recursos naturais de produção (quais sejam: solo, água, ar e organismos).

A evolução na produtividade ressaltada por Gasques et al. (2014) foi acompanhada pelo aumento nas vendas dos insumos necessários à produção agrícola. Em relação a 2012, os inseticidas representaram US \$ 3,606 bilhões, seguidos dos herbicidas com US\$3,315 bilhões e dos fungicidas com US\$2,468 bilhões, indicando que a liderança brasileira no setor do agronegócio é dependente desses insumos, alguns destes importados. Porém, o uso intensivo e indiscriminado destes defensivos provocam a contaminação dos alimentos, do solo, da água e dos animais; a intoxicação de agricultores; a resistência de insetos pragas, patógenos e plantas invasoras aos princípios ativos; a intensificação do surgimento de doenças iatrogênicas e da ressurgência de pragas; o desequilíbrio biológico, alterando a ciclagem de nutrientes e da matéria orgânica; a eliminação de organismos benéficos e a redução da biodiversidade (BETTIOL et al., 2014).

Consequentemente, o uso intensivo de agrotóxicos na produção agrícola é preocupante no cenário brasileiro, pois interfere diretamente no contexto da segurança dos alimentos. O controle do uso de agrotóxicos no país é realizado pela Agência Nacional de Vigilância Sanitária (ANVISA), por meio do Programa de Análise de Resíduos de Agrotóxicos em Alimentos (PARA), criado em 2001, justamente para monitorar a qualidade dos alimentos. Os relatórios fornecidos pela ANVISA apresentam dados que podem relacionar o uso de agrotóxicos e seus impactos na saúde da população, uma vez que seu uso crescente - e além do permitido pelas normas - apresenta riscos à segurança dos alimentos (ANVISA, 2013). 
De acordo com Carneiro et al. (2015), um terço dos alimentos consumidos no Brasil está contaminado por agrotóxicos, além da contaminação das águas, causando danos à saúde e também ao meio ambiente. O consumo médio de agrotóxicos está aumentando em relação à área plantada, isto é, em 2012 eram utilizados 10,5 (l/ha), já em 2011 passaram a ser utilizados 12,1 (l/ha). Esse aumento possui relação com diversos fatores, no entanto, para o presente artigo, vale destacar que o estímulo ao consumo se originou, principalmente, da redução dos preços e da ilógica isenção de impostos sobre os agrotóxicos, incentivando os agricultores a empregarem maior quantidade por hectare. Cerca de " $80 \%$ dos agrotóxicos consumidos no Brasil em 2013 foram utilizados pelas culturas de soja, cana-de-açúcar, milho e algodão" (CARNEIRO et al., 2015, p. 37).

Para Aguiar Menezes (2003), na tentativa de minimizar os impactos negativos causados pelos agrotóxicos, o controle biológico pode ser um instrumento crucial no manejo de pragas na agricultura, por possuir um custo relativamente menor e por representar um risco menor à contaminação e, consequentemente, à saúde humana e ao meio ambiente. Entretanto, a utilização do controle biológico deve ser associada a outros métodos de controle (químico) para manter a densidade populacional dos patógenos e insetos inferior ao nível de dano econômico. Gallo et al. (2002) explicam que o controle de pragas e doenças deve ser realizado por meio do Manejo Integrado de Praga (MIP), que envolve o uso de diversos agentes de controle, sendo um deles o biológico, no intuito de reduzir a população de uma espécie-alvo que potencialmente pode acarretar danos econômicos às lavouras.

O controle biológico consiste no uso de inimigos naturais, como parasitoides para manter a baixa densidade o nível de organismos prejudiciais às plantas, $\mathrm{e}$ compostos secundários de plantas em extratos vegetais ou fungos, com ações alelopáticas e biocidas, sendo biodegradáveis; ou o uso de iscas com feromônios dos insetos. Estas técnicas asseguram o equilíbrio natural entre os microrganismos e representam um método de controle que se baseia no estudo da relação entre os seres vivos no meio ambiente, a qual é reproduzida por cientistas em condições experimentais para posterior utilização no campo. $\mathrm{O}$ uso desse método contribui para a melhoria da qualidade do produto agrícola sem liberar resíduos nos alimentos, sendo inofensivos ao meio ambiente e à saúde da população. Esse método de 
controle é fortalecido pela atual e progressiva demanda por alimentos orgânicos e/ ou produzidos com menos agrotóxicos (PARRA et al., 2002).

A regulamentação para utilização do controle biológico no Brasil é expedida pelo Decreto $n^{0} 4.074$ (BRASIL, 2002) que regulamenta a Lei $n^{0} 7.802$ (BRASIL, 1989) sobre as pesquisas, uso e fiscalização dos agrotóxicos, seus componentes e afins. No Decreto, por meio do Art. $1^{\mathrm{o}}$, III, entende-se como agente biológico de controle o organismo vivo, de ocorrência natural ou obtida por manipulação genética, introduzido no ambiente para o controle de uma população ou de atividades biológicas de outro organismo vivo considerado nocivo.

As primeiras ocorrências da introdução do controle biológico na cultura da cana foram realizadas pela Copersucar e pelo Departamento de Entomologia da ESALQ/USP, no início da década de 1970. O programa de controle biológico da broca de açúcar desenvolvido pelo IAA/Planalsucar iniciou com o estudo de opções de controle e levantamento de intensidade de infestação da praga. Nas primeiras tentativas foram introduzidas parasitoides importados de Cuba, Lixophaga diatraeae (Towns); produção de taquinídeos nativos (Lydella minensense (Town) e Paratheresia claripalpis (Wulp)), não obtendo resultados significativos. Apenas a partir da segunda metade dos anos 70 ocorreram os aperfeiçoamentos na tecnologia que permitiram a produção em laboratório e a melhor eficiência dos resultados no campo, com a utilização da $C$. flavipes para controle biológico da D. Saccharalis (PARRA et al., 2002).

Também com base em Parra et al. (2002) pode-se definir quatro tipos de controle biológico:

I. Controle Biológico Artificial: produção artificial para acréscimo de seres parasitoides ou patogênicos e predadores para controle biológico natural, por meio de bactérias, nematoides, insetos, fungos, vírus e ácaros;

II. Controle Biológico Clássico: incorporação de parasitoides ou predadores por meio de colonização ou importação. A soltura dos indivíduos é reduzida no local, como um meio de controle de longo prazo, já que a população dos agentes controladores tende a se ampliar exponencialmente ao longo do tempo e, desse modo, apenas se emprega em determinadas culturas (perenes ou semi-perenes); 
III. Controle Biológico Natural: esse tipo de controle acontece de forma natural no local de origem e permite o equilíbrio de pragas por agentes nativos na área.

IV. Controle Biológico Aplicado: neste tipo de controle, inicialmente, há criação em laboratório em larga escala para comercialização dos agentes biológicos no mercado. São os denominados inseticidas biológicos. Um ausente e/ou deficiente manejo de doenças em plantas pode resultar em um rápido acúmulo de patógenos do solo em detrimento aos microrganismos benéficos das plantas. A importância dos patógenos habitantes do solo se dá pela sua sobrevivência no solo por vários anos, por meio de estruturas de resistência (escleródios ou clamidósporos), e em geral alta agressividade. Assim, não há resistência genética para a maioria das doenças causada por estes organismos nos cultivares disponíveis. Contudo, estes patógenos possuem dezenas de espécies de fungos e de bactérias antagônicas, chamados de agentes de controle biológico ou biocontroladores (LOBO JÚNIOR, 2016). O controle biológico no combate das doenças nas plantas, segundo Paula Júnior et al. (2016), pode ser acompanhado por práticas culturais agronômicas capazes de criar um ambiente favorável aos antagonistas e à resistência da planta hospedeira, ou ambas. Uma das práticas que pode ser usada em sinergia com o controle biológico é o uso de variedades resistentes. Outras medidas de controle são: uso de mudas sadias, tratamento térmico de mudas, escolha do local, época de plantio e manejo da época de colheita, adubação balanceada, controle de pragas como a broca da cana-de-açúcar e pulgões. Ou ainda, outra estratégia envolvente é a realização de roguing (eliminação de plantas doentes), para evitar que o agente causal esteja disperso das plantas afetadas para as sadias e em áreas não afetadas.

No Brasil, o programa de controle biológico mais eficiente e que está entre os melhores do mundo, é conduzido para controlar as principais pragas que assolam a cultura canavieira, sendo elas: $D$. saccharalis e $M$. fimbriolata. Para controlar a $D$. saccharalis, 3,3 milhões de hectares estão sendo tratados com $C$. flavipes. Em 2010, T. galloi também foi usado em 500.000 ha de cana-de-açúcar para controlar os ovos da broca de cana. Já a Mabanarva fimbriolata é controlada com o fungo 
M. anisopliae, cobrindo uma área de 2 milhões de hectares. O controle de pragas por método biológico na cultura canavieira corresponde a aproximadamente $45 \%$ da área total cultivada, sendo 39\% por Cotesia flavipes e 6\% Trichogramma galloi; $11 \%$ controlada por método químico e $44 \%$ correspondem às áreas não tratadas (PARRA, 2014).

Halfeld-Vieira et al. (2016) apresentam números muito próximos com relação ao uso do Metarbizium anisopliae para 3 milhões de hectares para controle de Mahanarva fimbiolata, e a Cotesia flavipes utilizada em 3,2 milhões de hectares para controle de Diatraea saccharalis.

Nessa conjuntura, as seguintes vantagens do emprego do controle biológico podem ser destacadas:

a) Promove o equilíbrio do ecossistema, com efetivos resultados na redução dos impactos ambientais, que ocorre devido à preservação de inimigos naturais, com poucos casos de resistência de pragas (CONCEIÇÃO; MEDEIROS DA SILVA, 2011);

b) Proporciona maior segurança no trabalho dos operadores por não necessitar manipular biocidas químicos ou aspergir sobre a lavoura;

c) Redução de custos pela adoção da tecnologia (FRONZAGLIA, 2006);

d) Relação custo/benefício favorável, por meio do incremento da produção durante todo o processo de cultivo (CONCEIÇÃO; MEDEIROS DA SILVA, 2011; BETTIOL; MORANDI, 2009);

e) Segurança dos alimentos, sem a presença de resíduos de agrotóxicos, com manutenção da qualidade nutricional, consequentemente, favorável à saúde da população (ERTHAL JUNIOR, 2011; PARRA et al., 2002).

Não obstante, foi identificada apenas uma desvantagem no uso do controle biológico. Conforme explica Erthal Junior (2011), a introdução de um organismo controlador pode, futuramente, se tornar uma praga ou então afetar indiretamente outras espécies nativas. Neste sentido, para a escolha de qualquer método de controle biológico devem-se respeitar dois aspectos primordiais, sendo: decisões técnicas econômicas (prejuízos causados pela praga e o custo total do método); e 
a relação do custo e benefício. A eficiência do controle biológico resulta da comparação que tem sido feita com o método químico (tradicional) no controle de pragas e doenças. Portanto, o método de controle biológico pode ser interpretado como alternativa de manejo e direciona ações para um modelo de agricultura sustentável.

\subsection{IMPORTÂNCIA ECONÔMICA DO CONTROLE DE PRAGAS NO CULTIVO DA CA- NA-DE-AÇÚCAR NO BRASIL}

No Brasil, os impactos negativos das pragas e doenças no sistema produtivo se caracterizam pela queda da produtividade agrícola, redução da longevidade dos canaviais, redução da qualidade da matéria-prima e elevado prejuízo econômico. Como o rendimento da cana é mais industrial que o potencial obtido por toneladas por unidade de área, o ataque severo das pragas provoca uma inversão da sacarose, contaminação de caldo por microrganismos e, consequentemente, a queda do rendimento industrial. Dessa forma, estima-se que a ação das pragas cause um prejuízo econômico em torno de 8,3 bilhões de reais por ano, conforme apresentado na Tabela 1, fato esse que orienta o setor canavieiro a adotar medidas mais eficientes e efetivas no controle de pragas, com vista a ampliar a produtividade por hectare (ARRIGONI, 2016).

Tabela 1. Prejuízos causados pelas pragas na cana-de-açúcar (potencial)

(Continua)

Praga Área de ocorrência

Prejuízos

Prejuízo total

\begin{tabular}{lrrr} 
& (ha x 1000) & $\mathbf{R} \$ \mathbf{h a} / \mathbf{a n o}$ & (milhões de reais) \\
\hline Broca da Cana & 9000 & 370 & 3330 \\
Cigarrinhas & 4000 & 590 & 2360 \\
Pragas de solo & 1800 & 420 & 756 \\
Migdolus & 500 & 1270 & 635 \\
Broca Gigante & 850 & 630 & 536 \\
\hline \multicolumn{1}{c}{ Praga } & Área de ocorrência & Prejuízos & Prejuízo total \\
& (ha x 1000) & R\$/ha/ano & (milhóes de reais) \\
\hline Sphenophorus & 500 & 1060 & 530 \\
Saúvas & 800 & 210 & 168 \\
\hline Total anual & & & $\mathbf{8 3 1 5}$ \\
\hline
\end{tabular}

Fonte: Elaborado com base em Arrigoni (2016). 
De acordo com informações coletadas junto a Semmelroth $(2016)^{7}$, com respeito aos métodos do controle de pragas na cana-de-açúcar, conclui-se que o custo de aplicação por hectare no controle químico é mais elevado em comparação ao biológico. Com base na Tabela 2, o controle químico corresponde a valores na ordem de 180 a $250 \mathrm{R} \$$ /ha, com um investimento de 144 a 200 milhões, em detrimento do controle biológico que corresponde a custos na ordem de 16 a $25 \mathrm{R} \$ / \mathrm{ha}$ e o investimento neste método de controle se situa em valores na faixa de 12 a 20 milhões. Se considerados os valores médios, o montante a ser gasto com controle biológico corresponde a 9,53\% do custo total do método químico por hectare e 9,30\% em relação ao montante necessário de investimentos.

Tabela 2. Estimativas gerais de custos de aplicação de controle químico e biológico

\begin{tabular}{crrr}
\hline Itens & $\mathbf{R} \$ \mathbf{h a}$ & Área coberta & Investimento \\
\hline Controle químico & 180 a 250 & 80 a $100 \%$ & 144 a 200 milhões \\
Controle biológico & 16 a 25 & 60 a $100 \%$ & 12 a 20 milhões \\
\hline
\end{tabular}

Fonte: Elaborado com base em Semmelroth (2016).

O impacto econômico negativo provocado pelas diversas pragas na cana decorrente da redução na produção varia com os tipos de pragas presentes na área plantada e o nível de infestação. Segundo Macedo (2005), as principais pragas e as estimativas das perdas geradas são sintetizadas a seguir:

- Broca da cana-de-açúcar (Diatraea saccharalis): para cada $1 \%$ de infestação ocorrem perdas médias de $0,77 \%$ na produção de cana, acrescidas de $0,25 \%$ na produção de açúcar e $0,20 \%$ na produção de etanol. O parasitoide mais utilizado para seu controle é a vespa Cotesia flavipes. Já em relação às lagartas desfolhadoras, há cinco espécies de lagartas que provocam a desfolha na cana-de-açúcar, sendo que não há um controle eficiente deste tipo de praga devido à dificuldade de detecção.

- Cigarrinha das raízes da cana-de-açúcar (Mahanarva fimbriolata): a de-

7 As informações utilizadas para construção deste artigo foram fornecidas pela Associação de Produtores de Bioenergia do Mato Grosso do Sul (BIOSUL), por meio de um documento interno disponibilizado pela instituição e apresentado no I Workshop EMBRAPA de Controle Biológico do Mato Grosso do Sul, realizado no ano de 2016. 
pender da densidade populacional, esta praga pode gerar perdas consideráveis de, em média, 15 toneladas de cana/ha/ano. Assim como a diminuição de 1,5 ponto percentual no teor de açúcar. A utilização do fungo Metarbizium anisopliae é o método biológico mais eficiente economicamente.

- Formigas cortadeiras (as principais são Atta bisphaerica e A. capiguara): elas representam perda de três toneladas de cana-de-açúcar em cada safra e perda na qualidade da matéria-prima pela diminuição do teor de sacarose, causadas por cada sauveiro adulto. As estimativas são de que o nível médio de infestação seja de 0,5 a 0,7 sauveiro adulto por ha, correspondendo a perdas de 1,5 a 2,1 toneladas de cana por ha/ano nas áreas afetadas.

- Broca do rizoma da cana-de-açúcar (Migdolus fryanus): na fase larval provoca danos ao sistema radicular da cana-de-açúcar e provoca sintomas de seca. Na média, gera uma diminuição de 30 toneladas por ha/ano nas áreas afetadas.

- Bicudo da cana-de-açúcar (Sphenophorus levis): ele provoca danos aos perfilhos e na base dos colmos em desenvolvimento, gerando uma redução de 20 a 23 toneladas de cana por ha/ano nas áreas afetadas.

- Cupins e outras pragas: estima-se que provocam perdas de, em média, 10 toneladas de cana por ha/ano nas áreas afetadas. Utilizando o método de monitoramento de pragas de solo foi possível diminuir o controle químico em $70 \%$, diminuindo também os custos e os riscos ambientais e sociais ${ }^{8}$.

A análise individualizada das pragas, nível de infestação e prejuízo econômico estão sumarizados na Tabela 3:

8 Para mais detalhes sobre as principais pragas e formas de controle biológico na cultura canavieira, ver, dentre outros: PARRA (2002; 2014) e MACEDO (2005). 
Tabela 3. Impacto econômico potencial segundo o nível de infestação e redução no rendimento das principais pragas

\begin{tabular}{|l|c|c|}
\hline PRAGAS & REFERÊNCIA & EM R\$ \\
\hline \multirow{3}{*}{ Broca } & Índice de infestação de referência $<3 \%$ & 113 milhões \\
\cline { 2 - 3 } & Grau de infestação baixo (até 5\%) & 189 milhões \\
\cline { 2 - 3 } & Grau de infestação elevado $(15 \mathrm{a} 25 \%)$ & 944 milhões \\
\hline \multirow{2}{*}{ Cigarrinha* } & $30 \%$ de queda na produtividade agrícola & $\begin{array}{c}1,12 \text { bilhão a } 1.560 \\
\mathrm{R} \$ / \mathrm{ha}\end{array}$ \\
\hline Migdolus e Sphenophorus & Redução de até $30 \mathrm{t} / \mathrm{ha}$ & $1.950 \mathrm{R} \$ / \mathrm{ha}$ \\
\hline Cupins e formigas $^{\text {Nematóide }}{ }^{1}$ & Redução de até $10 \mathrm{t} / \mathrm{ha}$ & $650 \mathrm{R} \$ \mathrm{ha}$ \\
\hline Redução de até $25 \mathrm{t} / \mathrm{ha}$ & $1.625 \mathrm{R} \$ / \mathrm{ha}$ \\
\hline
\end{tabular}

Fonte: Elaborado com base em Semmelroth (2016).

* O ataque da cigarrinha "pode resultar em perdas na produtividade agrícola que variam de $15 \%$ a $80 \%$ e na qualidade da matéria-prima com reduções de até 30\% no teor de sacarose" (PENATTI, 2006, p. 24).

A partir das informações apresentadas na Tabela 3, pode-se verificar que existe uma correlação entre o nível de infestação das pragas e o prejuízo econômico gerado. Portanto, o ataque severo das pragas na cana-de-açúcar pode comprometer o rendimento industrial tanto por meio da produção da cana-de-açúcar, quanto por meio do processo de transformação da sacarose. Portanto, a queda na produtividade agrícola da cultura canavieira e a redução no teor de sacarose oriundo dela reduzem a rentabilidade potencial do setor sucroalcooleiro.

Os impactos econômicos decorrentes do uso do controle biológico no Brasil ainda são precariamente divulgados, isto se deve à dificuldade para obtenção de dados, o que resulta na escassez de relatórios tanto técnicos quanto acadêmicos que podem comprovar a eficiência deste método. Para o uso eficiente de controle biológico, também é imprescindível a realização de investimentos em pesquisa e tecnologia, principalmente pelos órgãos financiadores, na tentativa de oferecer ainda mais vantagens em relação aos custos, em contrapartida a outros métodos (FRONZAGLIA, 2006). 


\section{REVISÃO DE LITERATURA}

Com o objetivo de ressaltar o grau de relevância sobre pesquisas acadêmicas apresentadas a partir do uso controle biológico na cana-de-açúcar, foi realizada uma revisão de literatura com a finalidade de quantificar o número de artigos (em periódicos) que foram publicados sobre o controle biológico na cultura canavieira e sua relação com a produtividade e custos econômicos. A pesquisa foi realizada entre os meses de junho e agosto de 2017, em quatro portais eletrônicos: Portal Capes; Web of Science; Science Direct; e Scopus. Os itens compilados para análise foram: autor(es); título do artigo; ano de publicação; e periódico. Como filtros para a pesquisa foram selecionadas seis palavras-chave (português e inglês): controle biológico; cana-de-açúcar; produtividade; custos de produção; biopesticidas e aspectos econômicos. Outro aspecto considerado na tabulação dos dados foi a classificação de cada periódico (Qualis), que representa substancialmente a qualidade dos artigos publicados.

Durante a pesquisa nos portais já referenciados, vários artigos se apresentaram no contexto da temática, contudo, utilizou-se como critério a escolha de artigos cujo tema aborda diretamente o controle biológico na cana-de-açúcar e sua relação com os impactos na produtividade e nos custos de produção9 ${ }^{9}$ É importante esclarecer que a data de publicação não foi um determinante dos autores, contudo, percebe-se que as primeiras publicações sobre o tema decorrem da década de 1990. Os resultados estão evidenciados no Quadro 1, ordenados em ordem decrescente conforme a classificação da CAPES (nas áreas de ciências agrárias e ciências ambientais).

9 Durante a pesquisa, nos portais indicados, foram encontrados muitos artigos que abordam os aspectos biológicos da cana-de-açúcar, como a fitologia, os quais não foram selecionados porque não estão diretamente relacionados à temática do artigo. 
Quadro 1. Resultado da revisão de literatura sobre o controle biológico na cana-de-açúcar e sua relação com a produtividade e aspectos econômicos

\begin{tabular}{|c|c|c|c|c|}
\hline Autor(es) & Título da publicação & Periódico & $\begin{array}{l}\text { Ano/publi- } \\
\text { cação }\end{array}$ & Qualis \\
\hline HEARNE, J. W.; & \multirow{3}{*}{$\begin{array}{l}\text { Determining strategies for the biological } \\
\text { control of a sugar cane stalk borer }\end{array}$} & \multirow{3}{*}{$\begin{array}{l}\text { Ecological } \\
\text { Modelling }\end{array}$} & \multirow{3}{*}{1994} & \multirow{3}{*}{$\mathrm{A} 1$} \\
\hline VAN COLLER, L. M.; & & & & \\
\hline CONLONG, D. E. & & & & \\
\hline NARANJO, S. E.; & \multirow{3}{*}{$\begin{array}{c}\text { Economic value of biological control in } \\
\text { integrated pest management of managed } \\
\text { plant systems }\end{array}$} & \multirow{3}{*}{$\begin{array}{c}\text { Annual } \\
\text { Review of } \\
\text { Entomol- } \\
\text { ogy }\end{array}$} & \multirow{3}{*}{2015} & \multirow{3}{*}{$\mathrm{A} 1$} \\
\hline ELLSWORTH, P. C.; & & & & \\
\hline FRISVOLD, G. B. & & & & \\
\hline OLIVEIRA, C. M.; & \multirow{4}{*}{$\begin{array}{l}\text { Crop losses and the economic impact of } \\
\text { insect pests on Brazilian agriculture }\end{array}$} & \multirow{4}{*}{$\begin{array}{l}\text { Crop Pro- } \\
\text { tection }\end{array}$} & \multirow{4}{*}{2014} & \multirow{4}{*}{ A1 } \\
\hline AUAD, A. M.; & & & & \\
\hline MENDES, S. M.; & & & & \\
\hline FRIZZAS, M. R. & & & & \\
\hline DASRAT, B.; & \multirow{5}{*}{$\begin{array}{l}\text { Evaluation of Allorhogas pyralopha- } \\
\text { gus Marsh (Hymenoptera: Braconidae) } \\
\text { for the biological control of Diatraea spp. } \\
\text { (Lepidoptera: Pyralidae) in sugar-cane } \\
\text { in Guyana }\end{array}$} & \multirow{5}{*}{$\begin{array}{l}\text { Crop Pro- } \\
\text { tection }\end{array}$} & \multirow{5}{*}{1997} & \multirow{5}{*}{$\mathrm{A} 1$} \\
\hline RAJKUMAR, A.; & & & & \\
\hline RICHARDS-HAYNES, C.; & & & & \\
\hline QUASHIE-WILLIAMS, C.; & & & & \\
\hline EASTWOOD, D. & & & & \\
\hline ZECHENDORF, B. & $\begin{array}{l}\text { Sustainable development: how can } \\
\text { biotechnology contribute? }\end{array}$ & $\begin{array}{l}\text { Trends in } \\
\text { Biotech- } \\
\text { nology }\end{array}$ & 1999 & A1 \\
\hline HORTON, P. M.; & \multirow{6}{*}{$\begin{array}{l}\text { Investigating strategies for minimising } \\
\text { damage caused by the sugarcane pest } \\
\text { Eldana saccharina }\end{array}$} & \multirow{6}{*}{$\begin{array}{l}\text { Agricultur- } \\
\text { al sistems }\end{array}$} & \multirow{6}{*}{2002} & \multirow{6}{*}{$\mathrm{A} 2$} \\
\hline HEARNEA, J. W.; & & & & \\
\hline APALOOA, J.; & & & & \\
\hline CONLONG, D. E.; & & & & \\
\hline WAYB, M. J.; & & & & \\
\hline UYSA, P. & & & & \\
\hline AMBROSANO, E. J.; & \multirow{10}{*}{$\begin{array}{l}\text { Produtividade da cana-de-açúcar após o } \\
\text { cultivo de leguminosas }\end{array}$} & \multirow{10}{*}{ Bragantia } & \multirow{10}{*}{2011} & \multirow{10}{*}{$\mathrm{B} 1$} \\
\hline HEITOR, C.; & & & & \\
\hline AMBROSANO, G. M. B.; & & & & \\
\hline SCHAMMAS, E. A.; & & & & \\
\hline DIAS, F. L. F.; & & & & \\
\hline ROSSI, F.; & & & & \\
\hline TRIVELIN, P. C. O.; & & & & \\
\hline MURAOKA, T; & & & & \\
\hline SACHS, R. C. C.; & & & & \\
\hline AZCÓN, R. & & & & \\
\hline
\end{tabular}


(Continua)

\begin{tabular}{|c|c|c|c|c|}
\hline Autor(es) & Título da publicação & Periódico & $\begin{array}{l}\text { Ano/publi- } \\
\text { cação }\end{array}$ & Qualis \\
\hline CARLINI-GARCIA, L.; & \multirow{3}{*}{$\begin{array}{l}\text { A integração tecnológica visando aumen- } \\
\text { to de produtividade em cana-de-açúcar }\end{array}$} & \multirow{3}{*}{$\begin{array}{l}\text { Pesquisa \& } \\
\text { Tecnologia }\end{array}$} & \multirow{3}{*}{2016} & \multirow{3}{*}{ B1 } \\
\hline XAVIER, M. A.; & & & & \\
\hline LANDELL, M. G. & & & & \\
\hline ALMEIDA SILVA, M. de.; & \multirow{3}{*}{$\begin{array}{c}\text { Produtividade e qualidade tecnológica da } \\
\text { soqueira de cana-de-açúcar submetida a } \\
\text { aplicação de biorregulador e fertilizantes } \\
\text { líquidos }\end{array}$} & \multirow{3}{*}{$\begin{array}{l}\text { Ciência } \\
\text { Rural }\end{array}$} & \multirow{3}{*}{2010} & \multirow{3}{*}{ B1 } \\
\hline CONSORTE CATO, S.;- & & & & \\
\hline GUERREIRO, A. F. C. & & & & \\
\hline AMBROSANO, G. M.; & \multirow{5}{*}{$\begin{array}{l}\text { Modelo matemático para simulação do } \\
\text { controle biológico da broca-da-cana com } \\
\text { o parasitoide Trichogramma galloi: I. } \\
\text { Modelos conceituais }\end{array}$} & \multirow{5}{*}{ Bragantia } & \multirow{5}{*}{1996} & \multirow{5}{*}{ B1 } \\
\hline STIMAC, J. L.; & & & & \\
\hline SILVEIRA NETO, S.; & & & & \\
\hline IGUE, T.; & & & & \\
\hline NAGAI, V. & & & & \\
\hline DURIGAN, J. C.; & \multirow{3}{*}{$\begin{array}{l}\text { Densidades e manejo químico da tiririca } \\
\text { na produtividade de cana-de-açúcar }\end{array}$} & \multirow{3}{*}{$\begin{array}{c}\text { Planta } \\
\text { Daninha }\end{array}$} & \multirow{3}{*}{2005} & \multirow{3}{*}{ B1 } \\
\hline TIMOSSI, P. C.; & & & & \\
\hline CORREIA, N. M. & & & & \\
\hline VARGAS, G.; & \multirow{3}{*}{$\begin{array}{l}\text { Sugarcane stem borers of the Colombian } \\
\text { cauca river valley: current pest status, } \\
\text { biology, and control }\end{array}$} & \multirow{3}{*}{$\begin{array}{l}\text { Florida } \\
\text { Entomol- } \\
\text { ogist }\end{array}$} & \multirow{3}{*}{2015} & \multirow{3}{*}{$\mathrm{B} 1$} \\
\hline GÓMEZ, L. A.; & & & & \\
\hline MICHAUD, J. P. & & & & \\
\hline POLANCZYK, R. A.; & \multirow{2}{*}{$\begin{array}{l}\text { Biological control of agricultural pests: } \\
\text { principles and field applications }\end{array}$} & \multirow{2}{*}{ Ceres } & \multirow{2}{*}{2009} & \multirow{2}{*}{$\mathrm{B} 2$} \\
\hline PRATISSOLI, D. & & & & \\
\hline PARRA, J. A. P. & Biological control in Brazil: an overview & $\begin{array}{l}\text { Scientia } \\
\text { Agricola }\end{array}$ & 2014 & B2 \\
\hline ABREU, J. A. S.; & \multirow{3}{*}{$\begin{array}{l}\text { Controle biológico por insetos parasi- } \\
\text { toides em culturas agrícolas no Brasil: } \\
\text { revisão de literatura }\end{array}$} & \multirow{3}{*}{ Uningá } & \multirow{3}{*}{2015} & \multirow{3}{*}{ B4 } \\
\hline ROVIDA, A. F. S.; & & & & \\
\hline CONTE, $\mathrm{H}$. & & & & \\
\hline SILVA, A. B.; & \multirow{2}{*}{$\begin{array}{l}\text { Controle biológico de insetos-pragas e } \\
\text { suas perspectivas para o futuro }\end{array}$} & \multirow{2}{*}{$\begin{array}{l}\text { Agrope- } \\
\text { cuária } \\
\text { Técnica }\end{array}$} & \multirow{2}{*}{2015} & \multirow{2}{*}{ B4 } \\
\hline BRITO, J. M. & & & & \\
\hline NADEEM, S.; & \multirow{2}{*}{$\begin{array}{l}\text { Biological control of sugarcane borers } \\
\text { with inundative release of trichogramma } \\
\text { chilonis (ishii) (hymenoptera: tricho- } \\
\text { grammatidae) in farmer fields }\end{array}$} & & & \\
\hline HAMED, M. & & $\begin{array}{l}\text { Agriculture } \\
\text { Science }\end{array}$ & 2011 & B5 \\
\hline
\end{tabular}


(Conclusão)

\begin{tabular}{|c|c|c|c|c|}
\hline Autor(es) & Título da publicação & Periódico & $\begin{array}{l}\text { Ano/publi- } \\
\text { cação }\end{array}$ & Qualis \\
\hline LEAL, J. T.; & \multirow{5}{*}{$\begin{array}{l}\text { Influência da cigarrinha-das-raízes maha- } \\
\text { narva fimbriolata (stal, 1854) (hemipte- } \\
\text { ra:cercopidae) e seus métodos de con- } \\
\text { trole sobre a produtividade e a qualidade } \\
\text { da cana-de-açúcar }\end{array}$} & \multirow{5}{*}{ Nucleus } & \multirow{5}{*}{2008} & \multirow{5}{*}{ B5 } \\
\hline GINAK, S. G.; & & & & \\
\hline ROSSI, M. M.; & & & & \\
\hline MUTTON, M. R.; & & & & \\
\hline MUTTON, M. A. & & & & \\
\hline CONCEIÇÃO, L. L.; & \multirow{2}{*}{$\begin{array}{l}\text { O controle biológico e suas aplicações na } \\
\text { cultura de cana-de-açúcar }\end{array}$} & \multirow{2}{*}{$\begin{array}{l}\text { Campo } \\
\text { Digit@1 }\end{array}$} & \multirow{2}{*}{2011} & \multirow{2}{*}{ B5 } \\
\hline MEDEIROS DA SILVA, C. & & & & \\
\hline DOOKUN, A. & $\begin{array}{l}\text { Agricultural biotechnology in developing } \\
\text { countries }\end{array}$ & $\begin{array}{c}\text { Biotech- } \\
\text { nology } \\
\text { Annual } \\
\text { Review }\end{array}$ & 2001 & - \\
\hline
\end{tabular}

Fonte: elaboração própria, com base nos Portais Capes; Web of Science; Science Direct; e Scopus (2017).

A partir da Tabela 4 nota-se que foram selecionados 20 artigos nos quatro portais de pesquisa, que se destacaram no tema relacionado ao uso do controle biológico na cana-de-açúcar e, como consequência, os ganhos de produtividade. Dentre os 20 artigos selecionados, apenas um (5\%) não se encontra classificado pela CAPES; contudo, cinco (25\%) estão publicados em periódicos internacionais que possuem a classificação A1, nota máxima estabelecida pela CAPES e um (5\%) artigo possui Qualis A2. Dentre os seis artigos classificados como B1, cinco (25\%) estão publicados em periódicos nacionais e um (5\%) em periódico internacional. Já em relação aos classificados como B2 foram selecionados dois (10\%) artigos e ambos foram publicados em periódicos nacionais. O restante (25\%) foi classificado com Qualis B4 e B5.

A pesquisa revelou que 50\% dos artigos estão publicados em periódicos internacionais, enquanto os demais são de publicação nacional, o que representa destaque das pesquisas brasileiras na temática, mesmo que em periódicos classificados como B1, B4 e B5. Sobre o período de publicação, quatro artigos (20\%) foram publicados na década de 1990; seis (30\%) entre 2000 e 2010; e dez artigos (50\%) de 2011 a 2016. Este resultado pode indicar os avanços tecnológicos observados no 
uso do controle biológico, sendo assim, a partir da década de 2010 percebe-se maior interesse nas pesquisas e resultados deste método.

Com a revisão de literatura foi possível demonstrar que o tema controle biológico e seus aspectos econômicos são escassos nas abordagens de pesquisadores acadêmicos das áreas relacionadas à economia rural ou agronegócios. Ademais, o impacto econômico da utilização do controle biológico na cultura canavieira é abordado marginalmente pelos autores das ciências agrárias ligadas a entomologia, ecologia e engenharias.

\section{CONSIDERAÇÕES FINAIS}

A cultura canavieira desempenha um papel fundamental no agronegócio e na economia brasileira, isso pelo fato do setor sucroalcooleiro constituir uma base importante para geração de empregos e, consequentemente, contribuir com uma parcela significativa no PIB brasileiro. Neste sentido, o objetivo desse trabalho foi apresentar a importância da utilização do controle biológico na expansão e no aumento da produtividade da cultura canavieira nacional. A pesquisa utilizou enquanto metodologia o instrumento da revisão de literatura.

Apesar da tamanha importância econômica, a cana-de-açúcar possui uma natureza agrícola e os métodos tradicionais (químico) de produção que garantem uma produtividade satisfatória com respeito ao aspecto econômico. No entanto, os custos com agrotóxicos e os desdobramentos negativos relativos ao seu uso para o meio ambiente e para a sociedade têm tornado possível avaliar outras alternativas de controle de pragas e doenças. Em decorrência, percebe-se a oportunidade de desenvolvimento dos "biopesticidas", com tecnologia nacional e com a finalidade de substituir ou, pelo menos, minimizar o uso de agrotóxicos.

Nesse contexto, o controle biológico na cultura canavieira se apresenta como uma alternativa para controle de pragas de modo a, dependendo da praga, reduzir a utilização de agrotóxicos e, portanto, pelo aspecto econômico, ampliar a produtividade por área plantada e pelo teor de sacarose e, pelo aspecto ambiental, reduzir a contaminação do meio ambiente pelos agrotóxicos e seus efeitos diretos 
sobre a fauna, flora e sociedade.

Com relação aos resultados encontrados nesta pesquisa, sobre a importância do controle biológico na cultura canavieira no Brasil, deve-se ressaltar que a escolha de qualquer método de controle biológico precisa considerar dois aspectos fundamentais. $\mathrm{O}$ primeiro diz respeito às decisões técnicas econômicas e se refere aos resultados comparativos, em termos de custos de aplicação e supervisão, entre a adoção do controle biológico e/ou controle químico de pragas. Já o segundo aspecto se refere à análise de custo e benefício da utilização do controle biológico como uma alternativa de manejo e com vistas a direcionar suas respectivas ações para um modelo de agricultura com maior grau de sustentabilidade.

Em relação aos resultados observados na revisão de literatura, foram encontrados vinte artigos de circulação nacional e internacional sobre o controle biológico e seus aspectos econômicos. É evidente que este tema não tem sido frequentemente pesquisado por acadêmicos relacionados à economia rural e agronegócios e, também, possivelmente por não ser o foco da pesquisa, o aspecto econômico do emprego de controle biológico na produção canavieira é tratado marginalmente pelos acadêmicos relacionados às ciências agrárias.

Neste sentido, portanto, este artigo buscou contribuir para preencher essa lacuna acadêmica observada. No entanto, ainda há uma agenda de pesquisa a ser realizada para construir uma informação mais precisa sobre a extensão da utilização do controle biológico na cultura canavieira e seus desdobramentos econômicos e ambientais. Isto porquê, durante a realização deste estudo, foram encontrados vários obstáculos relacionados à dificuldade para coletar dados secundários ou mesmo conseguir informações de instituições relacionadas à utilização de controle biológico na produção da cana-de-açúcar, tais como a Associação de Produtores de Bioenergia do Mato Grosso do Sul (BIOSUL), Centro de Tecnologia Canavieira (CTC) e União da Indústria da Cana de Açúcar (UNICA). Dessa forma, como recomendações para futuras pesquisas, percebeu-se a necessidade de avaliar a evolução do controle biológico na cultura canavieira com base em dados primários. 


\section{REFERÊNCIAS}

ABREU, J. A. S.; ROVIDA, A. F. S.; CONTE, H. Controle Biológico por Insetos Parasitoides em Culturas Agrícolas no Brasil: Revisão de literatura. Revista Uningá, v. 22, n. 2, p. 22-25, abr./jun., 2015. Disponível em: http://www.mastereditora.com.br/ periodico/20150501_153730.pdf. Acesso em: 07 jul. 2017.

AGÊNCIA NACIONAL DE VIGILÂNCIA SANITÁRIA (ANVISA). Programa de análise de resíduos de agrotóxicos em alimentos - PARA. Relatório de atividades de 2011 e 2012. Gerência-Geral de Toxicologia. Brasília, 2013. Disponível em: http://portal.anvisa.gov.br/documents/111215/446359/Programa + de +An\%C3\%A1lise + de + Res\%C3\%ADduos + de + Agrot\%C3\%B3xicos + - + Relat\%C3\%B3rio $+2011+$ e $+2012+\% 281 \%$ C2\%BA+etapa\%29/d5e91ef0-4235-4872-b180-99610507d8d5. Acesso em: 08 fev. 2017.

AGUIAR MENEZES, E. de L. Controle biológico de pragas: princípios e estratégias de aplicação em ecossistemas agrícolas. Embrapa Agrobiologia-Documentos (INFOTECA-E), 2003. Disponível em: https://www.embrapa.br/busca-de-publicacoes/-/ publicacao/625667/controle-biologico-de-pragas-principios-e-estrategias-de-aplicacao-em-ecossistemas-agricolas. Acesso em: 02 jun. 2017.

ALMEIDA SILVA, M.; CONSORTE CATO, S.; GUERREIRO, A. F. C. Produtividade e qualidade tecnológica da soqueira de cana-de-açúcar submetida à aplicação de biorregulador e fertilizantes líquidos. Ciência Rural, v. 40, n. 4, 2010.

AMBROSANO, E. J. et al. Produtividade da cana-de-açúcar após o cultivo de leguminosas. Bragantia, v. 70, n. 4, p. 810-818, 2011.

ANDRADE, M. C. de. Espaço e tempo na agroindústria canavieira de Pernambuco Estudos Avançados, v. 15, n. 43, p. 267-289, Set./Dec. 2001.

ARAÚJO, C. A. Bibliometria: evolução histórica e questões atuais. Em questão, v. 12, n. $1,2006$.

ARRIGONI, E. de B. Controle Biológico da Cana de açúcar. In: WORKSHOP FAPESP DESAFIOS DA PESQUISA EM CONTROLE BIOLÓGICO NA AGRICULTURA NO ESTADO DE SÃO PAULO, 1., 2016, São Paulo. Anais [...]. São Paulo: FAPESP. Disponível 
em: http://www.fapesp.br/eventos/2016/02/cb/Enrico.pdf. Acesso em: 04 ago. 2017.

BACHA, C. J. C. Economia e política agrícola no Brasil. São Paulo: Atlas, 2012.

BETTIOL, W. et al. Control biológico de enfermedades de plantas en América Latina y el Caribe. Facultad de Agricultura, Universidad de la República, Montevideo, 2014.

BRASIL. Decreto ${ }^{0} 4.074$, de 04 de janeiro de 2002. Regulamenta a Lei ${ }^{0} 7.802$, de 11 de julho de 1989, que dispõe sobre a pesquisa, a experimentação, a produção, a embalagem e rotulagem, o transporte, o armazenamento, a comercialização, a propaganda comercial, a utilização, a importação, a exportação, destino final dos resíduos e embalagens, o registro, a classificação, o controle, a inspeção e a fiscalização de agrotóxicos, seus componentes e afins, e dá outras providências. Diário Oficial da República Federativa do Brasil, Brasília, 08 jan. 2002. Seção I, p. 1.

BRASIL. Lei $\mathrm{n}^{0}$ 7.802, de 11 de julho de 1989. Dispõe sobre agrotóxicos, seus componentes e afins. Diário Oficial da União, Brasília, 11 jul. 1989. Seção 1, p. 1145911460 .

BUAINAIN, A. M. et al. Sete teses sobre o mundo rural brasileiro. Revista de Política Agrícola, v. 22, n. 2, p. 105-121, 2013.

CARLINI-GARCIA, L. A.; XAVIER, M. A.; LANDELL, M. G. de A. A integração tecnológica visando aumento de produtividade em cana de-açúcar. Pesquisa \& Tecnologia. Informações tecnológicas, v. 13, n. 1, Jan./Jun., 2016. Disponível em: http://www. aptaregional.sp.gov.br/acesse-os-artigos-pesquisa-e-tecnologia/agregacao-de-valor-e-eng-de-alimentos/edicao-2016/janeiro-junho-4/1676-integracao-tecnologica-visando-aumento-de-produtividade-em-cana-de-acucar/file.html. Acesso em: 01 jun. 2017.

CARNEIRO, F. F. et al. Dossiê ABRASCO: um alerta sobre os impactos dos agrotóxicos na saúde. 2015. Disponível em: http://www.abrasco.org.br/dossieagrotoxicos/ wp-content/uploads/2013/10/DossieAbrasco_2015_web.pdf. Acesso em: 04 ago. 2017.

CENTRO DE ESTUDOS AVANÇADOS EM ECONOMIA APLICADA - CEPEA. PIB Agronegócio - BR. Piracicaba: ESALQ/USP, 2015. Disponível em: http://cepea.esalq. 
usp.br/pib/. Acesso em: 04 ago. 2017.

CONCEIÇÃO, L. L.; MEDEIROS DA SILVA, C. O controle biológico e suas aplicações na cultura de cana-de-açúcar. Campo Digit@1, v. 6, n. 1, p. 14-25, 2011.

DURIGAN, J. C.; TIMOSSI, P. C.; CORREIA, N. M. Densidades e manejo químico da tiririca na produtividade de cana-de-açúcar. Planta Daninha, p. 463-469, 2005.

EMPRESA BRASILEIRA DE PESQUISA AGROPECUÁRIA - EMBRAPA. Embrapa em números. Brasília, 2015. Disponível em: https://www.embrapa.br/documents/10180/1600893/Embrapa + em + N\%C3\%BAmeros/7624614b-ff8c-40c0-a87f-c9f00cd0a832. Acesso em: 10 ago. 2017.

ERTHAL JUNIOR, M. Controle Biológico de Insetos e Pragas. In: I SEMINÁRIO MOSAICO AMBIENTAL: OLHARES SOBRE O AMBIENTE, 2011. Anais [...] Campos dos Goytacazes, 2011. Disponível em: http://eventoscca.com.br/event/seciagra7/site/ download/2014\%20Anais\%20do\%20VII\%20SECIAGRA\%20e\%20IV\%20ERCA.pdf. Acesso em: 10 jul. 2017.

FRONZAGLIA, T. Avaliação e projeção do impacto econômico do controle biológico da cigarrinha da raiz na cana-de-açúcar (2000-2005). In: Simpósio de Gestão da Inovação Tecnológica, 24., 2006. Anais [...]. Gramado, 2006. Disponível em: http:// www.anpad.org.br/ anpad/eventos.php?cod_evento $=5 \&$ cod_edicao_subse$\mathrm{cao}=162 \&$ cod_evento_edicao $=19 \&$ cod_edicao_trabalho $=6358$. Acesso em: 10 jul. 2017.

FURTADO, C. Formação econômica do Brasil. 12. ed. Rio de Janeiro: Nacional, 1974. 248p.

GALLO, D. et al. Entomologia agrícola. 2. ed. Piracicaba: FEALQ, 2002.

GASQUES, J. G. et al. Produtividade da agricultura: resultados para o Brasil e estados selecionados. Revista de Política Agrícola, v. 23, n. 3, p. 87-98, 2014.

HALFELD-VIEIRA, B. A. et al. Defensivos agrícolas naturais: uso e perspectivas. Brasília: EMBRAPA, 2016. 
HEARNE, J. W.; VAN COLLER, L. M.; CONLONG, D. E. Determining strategies for the biological control of a sugarcane stalk borer. Ecological Modelling, v. 73, n. 1-2, p. 117-133, 1994.

HORTON, P. M. et al. Investigating strategies for minimising damage caused by the sugarcane pest Eldana saccharina. Agricultural Systems, v. 74, n. 2, p. 271-286, 2002.

LEAL, J. E. T. et al. Influência da cigarrinha-das-raízes mahanarva fimbriolata (Stal, 1854) (hemiptera: cercopidae) e seus métodos de controle sobre a produtividade e a qualidade da cana-de-açúcar. Nucleus, v. 5, n. 2, 2008.

MACEDO, I. de C. et al. A energia da cana-de-açúcar: doze estudos sobre a agroindústria da cana-de-açúcar no Brasil e a sua sustentabilidade. São Paulo: UNICA, 2005. Disponível em: . $<$ www.unica.com.br/download.php?idSecao=17\&id=2447557. $>$. Acesso em: 04 ago. 2017.

MARTHA-JÚNIOR, G. B.; ALVES, E.; CONTINI, E. Dimensão econômica de sistemas de integração lavourapecuária. Pesquisa Agropecuária Brasileira, v. 46, n. 10, p. 1117-1126, 2012. Disponível em: . < http://www.scielo.br/pdf/pab/v46n10/46v10a01. pdf. Acesso em: 11 ago. 2017.

BETTIOL, W.; MORANDI, M. A. B. Biocontrole de doenças de plantas: uso e perspectivas. 2009. Disponível em: . < http://bibliodigital.unijui.edu.br:8080/xmlui/bitstream/handle/123456789/2353/Biocontrole\%20de\%20doen\%C3\%A7as\%20de\%20 plantas.pdf?sequence =1. Acesso em: 15 jan. 2017.

NARANJO, S. E.; ELLSWORTH, P. C.; FRISVOLD, G. B. Economic value of biological control in integrated pest management of managed plant systems. Annual review of entomology, v. 60, p. 621-645, 2015.

NEVES, M. F.; CONEJERO, M. A. Estratégias para a cana no Brasil: um negócio classe mundial. São Paulo: Atlas, 2010.

OLIVEIRA, C. M. et al. Crop losses and the economic impact of insect pests on Brazilian agriculture. Crop Protection, v. 56, p. 50-54, 2014. 
PARRA, J. R. P. Biological control in Brazil: an overview. Scientia Agricola, v. 71, n. 5, out., 2014.

PARRA, J. R. P. et al. Controle Biológico no Brasil: parasitoides e predadores. São Paulo: Manole, 2002.

PAULA JÚNIOR et al. Manejo integrado de doenças e pragas utilizando controle biológico. In: VIEIRA et al. Defensivos agrícolas naturais: so e perspectivas. Brasília, 2016. Disponível em: http:/ainfo.cnptia.embrapa.br/digital/bitstream/ item/153291/1/2016LV01-1.pdf . Acesso em: 11 mar. 2018.

PENATTI, C. Cigarrinha das raízes da cana-de-açúcar. Revista Coplana, p. 24-25, nov. 2006. Disponível em: http://www.coplana.com/gxpfiles/ws001/design/revistacoplana/2006/novembro/pag24.pdf. Acesso em: 10 ago. 2017.

PEREIRA, P. A. A. et al. The development of Brazilian agriculture: future technological challenges and opportunities. Agriculture \& Food Security, v. 1, n. 1, p. 4 , 2012.

POLANCZYK, R. A.; PRATISSOLI, D. Biological control of agricultural pests: principles and field applications. Revista Ceres, v. 56, n. 4, 2009.

RENEWABLE FUELS ASSOCIATION - RFA. Industry Statistics, 2016. Disponível em: http://www.ethanolrfa.org/resources/industry/statistics/\#1454098996479-8715d404-e546. Acesso em: 04 ago. 2017.

SANTOS, L. P. et al. Agronegócio brasileiro no comércio internacional. Revista de Ciências Agrárias, v. 39, n. 1, p. 54-69, 2016.

SEMMELROTH, W. Demandas Fitossanitárias do setor produtivo: cana de açúcar. In: I WORKSHOP EMBRAPA DE CONTROLE BIOLÓGICO DO MATO GROSSO DO SUL, 1, 2016, Campo Grande. Anais [...] Campo Grande: EMBRAPA, FAMASUL, 2016. Disponível em: https:/www.embrapa.br/documents/1354395/1527093/I+Worksho$\mathrm{p}+\mathrm{de}+$ Controle + Biol\%C3\%B3gico $+\mathrm{de}+\mathrm{MS} / 612 \mathrm{e} 9 \mathrm{f} 6 \mathrm{f}-6380-4222-855 \mathrm{f}-819 \mathrm{e} 6 \mathrm{~b}-$ $\mathrm{c} 058 \mathrm{~b} 5$ ? $\mathrm{t}=1473364759164$. Acesso em: 11 jun. 2017.

SHIKIDA, P. F. A. Evolução e fases da agroindústria canavieira no Brasil. Revista de 
Política Agrícola, v. 23, n. 4, p. 43-57, 2015.

SILVA, A. B.; BRITO, J. M. Controle biológico de insetos-pragas e suas perspectivas para o futuro. Revista Agropecuária Técnica, v. 36, n. 1, p. 248-258, 2015.

UNIÃO DA INDÚSTRIA DE CANA-DE-AÇÚCAR - UNICA. Unicadata, 2015. Disponível em: http://www.unicadata.com.br. Acesso em: 04 ago. 2017.

VARGAS, G.; GÓMEZ, L. A.; MICHAUD, J. P. Sugarcane stem borers of the Colombian Cauca River Valley: current pest status, biology, and control. Florida entomologist, v. 98, n. 2 , p. $728-735,2015$.

Recebido em: 12/09/2017

Aceito em: 24/05/2018 